\title{
Exogenous hydrogen sulfide protects human umbilical vein endothelial cells against high glucose-induced injury by inhibiting the necroptosis pathway
}

\author{
JIAQIONG LIN ${ }^{1}$, MEIJI CHEN ${ }^{2}$, DONGHONG LIU ${ }^{3}$, RUIXIAN GUO ${ }^{4}$, KAI LIN $^{1}$, HAIOU DENG $^{1}$, \\ XIMEI ZHI ${ }^{1}$, WEIJIE ZHANG ${ }^{1}$, JIANQIANG FENG ${ }^{4}$ and WEN WU ${ }^{1}$ \\ ${ }^{1}$ Department of Endocrinology, Guangdong General Hospital, Guangdong Academy of Medical Sciences, \\ Guangdong Geriatrics Institute, Guangzhou, Guangdong 510080; ${ }^{2}$ Department of Pediatrics, \\ Huangpu Division of the First Affiliated Hospital, Sun Yat-sen University, Guangzhou, Guangdong 510700; \\ ${ }^{3}$ Department of Ultrasound, The First Affiliated Hospital, Sun Yat-sen University; ${ }^{4}$ Department of Physiology, \\ Zhongshan School of Medicine, Sun Yat-sen University, Guangzhou 510080, P.R. China
}

Received June 15, 2016; Accepted December 5, 2017

DOI: $10.3892 /$ ijmm.2017.3330

\begin{abstract}
Hyperglycemia is a key factor in the development of diabetic complications, including the processes of atherosclerosis. Receptor-interacting protein 3 (RIP3), a mediator of necroptosis, is implicated in atherosclerosis development. Additionally, hydrogen sulfide $\left(\mathrm{H}_{2} \mathrm{~S}\right)$ protects the vascular endothelium against hyperglycemia-induced injury and attenuates atherosclerosis. On the basis of these findings, the present study aimed to confirm the hypothesis that necroptosis mediates high glucose (HG)-induced injury in human umbilical vein endothelial cells (HUVECs), and that the inhibition of necroptosis contributes to the protective effect of exogenous $\mathrm{H}_{2} \mathrm{~S}$ against this injury. The results revealed that exposure of HUVECs to $40 \mathrm{mM}$ HG markedly enhanced the expression level of RIP3, along with multiple injuries, including a decrease in cell viability, an increase in the number of apoptotic cells, an increase in the expression level of cleaved caspase-3, generation of reactive oxygen species (ROS), as well as dissipation of the mitochondrial membrane potential (MMP). Treatment of the cells with sodium hydrogen sulfide (NaHS; a donor of $\mathrm{H}_{2} \mathrm{~S}$ ) prior to exposure to $\mathrm{HG}$ significantly attenuated the increased RIP3 expression and the aforementioned injuries by HG. Notably, treatment of cells with necrostatin-1 (Nec-1), an inhibitor of necroptosis, prior to exposure to HG ameliorated the $\mathrm{HG}$-induced injuries, leading to a decrease in ROS generation and a loss of MMP. However, pre-treatment of the cells with Nec-1 enhanced the HG-induced increase in the
\end{abstract}

Correspondence to: Dr Wen Wu, Department of Endocrinology, Guangdong General Hospital, Guangdong Academy of Medical Sciences, Guangdong Geriatrics Institute, 106 Zhong Shan Er Lu, Guangzhou, Guangdong 510080, P.R. China

E-mail:wuwen1964@163.com

Key words: hydrogen sulfide, high glucose, endothelial cells, necroptosis, receptor interacting protein 3 , interaction expression levels of cleaved caspases-3 and -9. By contrast, pre-treatment with Z-VAD-FMK, a pan -caspase inhibitor, promoted the increased expression of RIP3 by HG. Taken together, the findings of the present study have demonstrated, to the best of our knowledge for the first time, that exogenous $\mathrm{H}_{2} \mathrm{~S}$ protects HUVECs against $\mathrm{HG}$-induced injury through inhibiting necroptosis. The present study has also provided novel evidence that there is a negative interaction between necroptosis and apoptosis in the HG-treated HUVECs.

\section{Introduction}

Hyperglycemia, an important characteristic of diabetes mellitus, is considered to be a dangerous factor of diabetic complications. It is able to induce dysfunction of the vascular endothelium through various pathophysiological mechanisms, which are associated with atherosclerosis, leading to target organic impairment, such as blindness (1), kidney failure (2), and cardiovascular diseases (3). Hence, it is crucially important to protect endothelial cells against hyperglycemia-induced injury.

Numerous processes have been demonstrated to be associated with injury induced by hyperglycemia, including apoptosis (4), oxidative stress (5), and mitochondrial dysfunction (5). Traditionally, cell death was divided into three categories: Apoptosis, necrosis and autophagy. Apoptosis is an alternative term for programmed cell death, which allows cells to commit suicide according to a specifically designated program in the absence of inflammation. Autophagy is another mechanism, which leads to formation of autophagosomes in a dying cell to maintain homeostasis of the organism. By contrast, necrosis is regarded as a passive and unregulated form of cell death, which is characterized by early plasma membrane destruction and swelling of the intracellular organelles. However, necroptosis (also termed 'programmed necrosis') (6), a newly identified form of programmed cell death, has broken the traditionally understood concept of cell death. In contrast with apoptosis, necroptosis operates according to a caspase-independent 
mechanism. Receptor-interacting protein (RIP)1 and RIP3 serve a critical role as signal transducers in the pathway of necroptosis. Recently, significant progress has been made in the study of necroptosis. RIP3-mediated necroptosis has now been determined to be a common cell-death pathway implicated in cytokine-, virus-, and genotoxic stress-induced cell death, and has also been identified to participate in a variety of pathological conditions, including the immune response (7), multiple tissue injury (8), the retinal ischemia-reperfusion injury (9), and myocardial infarction (10). However, the role of necroptosis in hyperglycemia-induced injury of endothelial cells has yet to be fully elucidated.

Hydrogen sulfide $\left(\mathrm{H}_{2} \mathrm{~S}\right)$, previously regarded as a poisonous gas emitted from rotten eggs, has been demonstrated to be an endogenously produced, labile diffusible mediator with multiple roles in the cardiovascular system associated with health and disease (11-19), including vasodilation $(11,12)$ and the stimulation of angiogenesis (13). In recent years, more and more attention has been paid to the endothelial protective effect of $\mathrm{H}_{2} \mathrm{~S}$ against injuries. Mani et al (20) reported that decreased endogenous production of $\mathrm{H}_{2} \mathrm{~S}$ accelerates atherosclerosis. Upon application of $\mathrm{H}_{2} \mathrm{~S}$, the progression of atherosclerosis was inhibited in fat-fed apoE $\mathrm{E}^{-/-}$mice (21). Notably, it was shown that low levels of $\mathrm{H}_{2} \mathrm{~S}$ in the blood of patients with diabetes and streptozotocin-treated diabetic rats may be associated with vascular inflammation (22). Absence of cystathionine $\gamma$-lyase, a synthase of $\mathrm{H}_{2} \mathrm{~S}$, exacerbates hyperglycemic endothelial cell dysfunction (6). In addition, exogenous $\mathrm{H}_{2} \mathrm{~S}$ was shown to protect vascular endothelium against high glucose (HG)-induced injuries, including an overabundant generation of reactive oxygen species (ROS), a decrease in cell viability, and DNA injury, by preserving mitochondrial function (6). Since cardiac RIP3 expression was shown to be increased in diabetic rats (23), and RIP3 is involved in atherosclerosis development (24), the present study aimed to explore the influence of HG on the expression level of RIP3, and the role of necroptosis in the HG-induced injury, and to examine whether exogenous $\mathrm{H}_{2} \mathrm{~S}$ protects against HG-induced injury by inhibiting necroptosis in human umbilical vein endothelial cells (HUVECs).

\section{Materials and methods}

Materials and reagents. Sodium hydrogen sulfide (NaHS), necrostatin-1 (Nec-1), Z-VAD-FMK, Hoechst 33258, 2',7'-dichlorofluorescein diacetate (DCFH-DA) and rhodamine 123 (Rh123) were purchased from Merck KGaA (Darmstadt, Germany). Anti-cleaved caspase-3 antibody (cat. no. 9664) was procured from Cell Signaling Technology, Inc. (Boston, MA, USA); anti-RIP3 (ab56164) was purchased from Abcam (Cambridge, UK); and the anti-caspase-9 (10380-1-AP) and anti-GAPDH (10494-1-AP) antibodies were purchased from Proteintech Group, Inc. (Wuhan, China). The Cell Counting kit-8 (CCK-8) was obtained from Dojindo Laboratories (Kumamoto, Japan). Fetal bovine serum (FBS) and Gibco BRL ${ }^{\mathrm{TM}}$ Dulbecco's modified Eagle's medium (DMEM) were obtained from Thermo Fisher Scientific, Inc. (Waltham, MA, USA). Horseradish peroxidase -conjugated secondary antibody and the bicinchoninic acid (BCA) protein assay kit were obtained from KangChen Bio-tech,
Inc. (Shanghai, China). Enhanced chemiluminescence solution was purchased from Nanjing KeyGen Biotech Co., Ltd. (Nanjing, China). Lysis buffer was purchased from the Beyotime Institute of Biotechnology (Shanghai, China), and the HUVECs were supplied by Guangzhou Jiniou Co., Ltd. (Guangzhou, China).

Cell culture and treatments. HUVECs were cultured in DMEM medium at a concentration of $1 \times 10^{6}$ cells $/ \mathrm{ml}$, supplemented with $10 \% \mathrm{FBS}$ at $37^{\circ} \mathrm{C}$ under an atmosphere of $5 \% \mathrm{CO}_{2}$. To explore the protective effects of $\mathrm{H}_{2} \mathrm{~S}$ on HG-induced injury, cells were pretreated with $400 \mu \mathrm{M}$ NaHS (a well-known $\mathrm{H}_{2} \mathrm{~S}$ donor) for $30 \mathrm{~min}$ prior to $\mathrm{HG}$ treatment. To determine the role of necroptosis in HG-induced injury, HUVECs were pre-treated with Nec-1 (an inhibitor of necroptosis) prior to HG treatment. The culture medium was replaced with fresh medium every 2-3 days, and expanded to new culture vessels when the cells had reached $\sim 80 \%$ confluence.

Cell viability assay. HUVECs were cultured in 96-well plates at a concentration of $1 \times 10^{4}$ cells $/ \mathrm{ml}$. After incubation at $37^{\circ} \mathrm{C}$ for $24 \mathrm{~h}$ and receiving the specific treatments (as detailed in the results section), the cells were washed with phosphate-buffered saline (PBS), and $10 \mu \mathrm{l}$ CCK-8 solution was added to each well at a 10\% dilution for an $\sim 2 \mathrm{~h}$ incubation in the incubator. Absorbance was measured at $450 \mathrm{~nm}$ with a microplate reader (Multiskan MK3 Microplate reader; Thermo Fisher Scientific, Inc.). The mean optical density (OD) of three wells in the indicated groups was used to calculate the percentage of cell viability according to the following formula: Percentage of cell viability $(\%)=\left(\mathrm{OD}_{\text {treatment group }} / \mathrm{OD}_{\text {control group }}\right) \times 100 \%$. The experiment was repeated 5 times.

Hoechst 33258 nuclear staining for the assessment of apoptosis. Apoptotic cell death was assessed using the Hoechst 33258 staining method. The HUVECs were plated in $60 \mathrm{~mm}$ dishes at a density of $1 \times 10^{6}$ cells/well. After having performed the indicated treatments, the cells were harvested and fixed with paraformaldehyde in $0.1 \mathrm{~mol} / 1 \mathrm{PBS}$ for $10 \mathrm{~min}$. After rinsing 5 times with PBS, the nuclear DNA was stained with $5 \mathrm{mg} / \mathrm{ml}$ Hoechst 33258 dye for $10 \mathrm{~min}$, before being rinsed with PBS and then visualized under a fluorescence microscope (Bx50-FLA; Olympus Corporation, Tokyo, Japan). Viable HUVECs exhibited a uniform blue fluorescence throughout the nucleus, whereas apoptotic cells revealed fragmented and condensed nuclei. The experiment was repeated 5 times.

Measurement of intracellular ROS generation. Intracellular ROS generation was measured by oxidation of DCFH-DA to fluorescent 2',7' -dichlorofluorescein (DCF). The HUVECs were cultured on a slide in DMEM, supplemented with $10 \% \mathrm{FBS}$ at $37^{\circ} \mathrm{C}$ under an atmosphere of $5 \% \mathrm{CO}_{2}$. Following the different treatments, the slides were washed 3 times with PBS. DCFH-DA solution $(10 \mu \mathrm{M})$ in serum-free medium was added to the slides, and the cells were subsequently incubated at $37^{\circ} \mathrm{C}$ for $30 \mathrm{~min}$ in an incubator. The cells were washed 5 times with PBS, and DCF fluorescence was measured over the entire field of vision by using a fluorescence microscope 

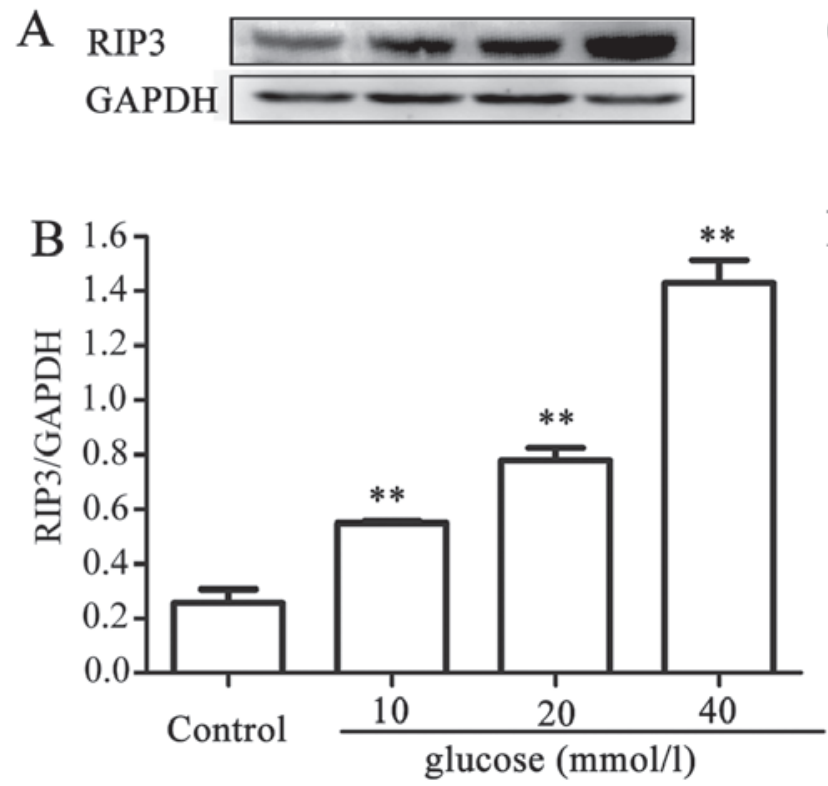
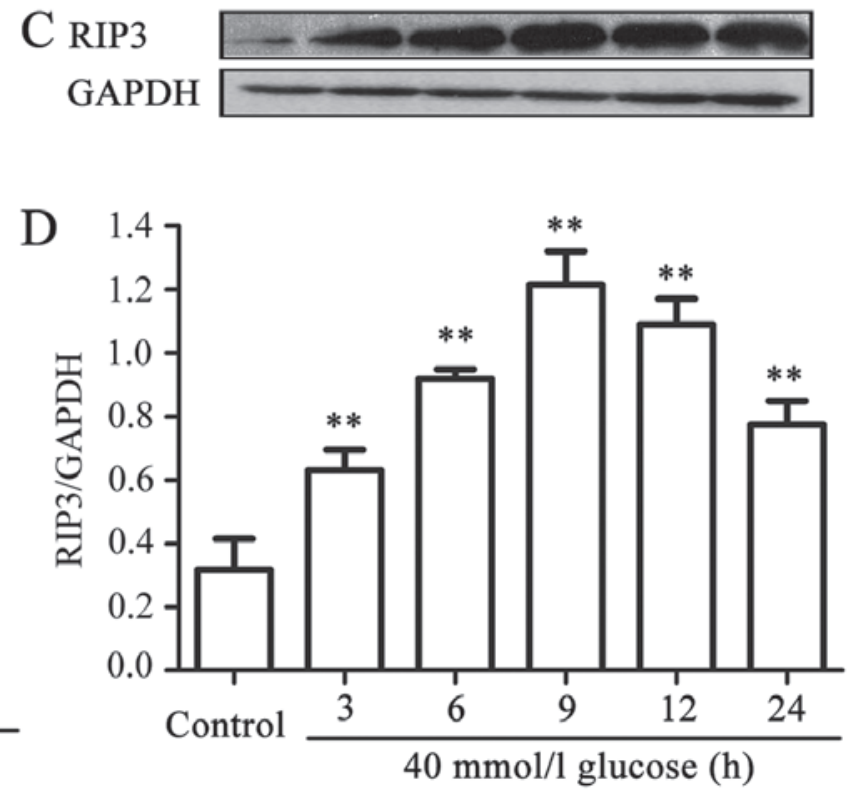

Figure 1. HG induces necroptosis in HUVECs. The expression level of RIP3 was quantified by western blot analysis assay. (A) The cells were exposed to the concentrations of glucose (mmol/l) indicated in (B) for $24 \mathrm{~h}$. (C) The cells were treated with $40 \mathrm{mM}$ HG for the times indicated in (D). (B and D) Densitometric analysis of the expression levels of RIP3 shown in (A) and (C). Data are presented as the mean \pm standard error of the mean ( $=3$ ). ${ }^{* *} \mathrm{P}<0.01 \mathrm{vs}$. the control group. HG, high glucose; RIP3, receptor -interacting protein 3; HUVECs, human umbilical vein endothelial cells.

connected to an imaging system (Bx50-FLA; Olympus Corporation). The mean fluorescence intensity (MFI) from five random fields was measured using ImageJ $1.47 \mathrm{i}$ software, and the MFI was used as an index of the amount of ROS. The experiment was performed 5 times.

Examination of the mitochondrial membrane potential (MMP). MMP was assessed using a fluorescent dye, Rh123. The depolarization of MMP results in a loss of MMP, and a decrease in green fluorescence. The cells were cultured on a slide with DMEM, supplemented with $10 \% \mathrm{FBS}$ at $37^{\circ} \mathrm{C}$ under an atmosphere of $5 \% \mathrm{CO}_{2}$. Following the indicated treatments, the slides were washed 3 times with PBS. The cells were incubated with $1 \mu \mathrm{M}$ Rh123 at $37^{\circ} \mathrm{C}$ for $30 \mathrm{~min}$ in an incubator, and then washed briefly 5 times with PBS. Fluorescence was subsequently measured over the whole field of vision using a fluorescence microscope connected to an imaging system (Bx50-FLA; Olympus Corporation). The MFI of Rh123 from five random fields was analyzed using ImageJ 1.47i software, and the MFI was used as an index of the levels of MMP. The experiment was performed 5 times.

Western blot analysis assay. After the indicated treatments, the HUVECs were harvested and lysed with cell lysis for $30 \mathrm{~min}$ at $4^{\circ} \mathrm{C}$. The total protein in the supernatant was quantified with a BCA protein assay kit. Total protein ( $30 \mu \mathrm{g}$ from each sample) was separated using $12 \%$ SDS-PAGE. The protein in the gel was transferred to a polyvinylidene difluoride membrane. The membrane was blocked with $5 \%$ fat-free milk for $60 \mathrm{~min}$ at room temperature, and then incubated with primary antibodies specific to anti-cleaved caspase-3 (1:1,000), anti-caspase-9 $(1: 2,500)$, RIP3 $(1: 1,000)$, or GAPDH $(1: 5,000)$, with slow agitation at $4^{\circ} \mathrm{C}$ overnight. Following three washes with TBS/ Tween 20 (TBS-T), the proteins were subsequently incubated with the secondary antibodies for $60 \mathrm{~min}$ at room temperature.
Following three washes with TBS-T for 15 min, membranes were visualized by enhanced chemiluminescence and exposure to X-ray films. To quantify protein expression, the X-ray films were scanned and analyzed using ImageJ $1.47 \mathrm{i}$ software. Each experiment was repeated 3 times.

Statistical analysis. All data are presented as the means \pm SEM. Differences between groups were analyzed using one -way analysis of variance using SPSS 20.0 software (IBM Corp., Armonk, NY, USA), followed by the least significant difference (LSD) post hoc comparison test. $\mathrm{P}<0.05$ was considered to indicate a statistically significant difference.

\section{Results}

HG upregulates the expression level of RIP3 in HUVECs. In order to explore the effects of HG on necroptosis in HUVECs, dose- and time -response experiments to determine the effects of different concentrations of glucose on the expression level of RIP3, a kinase promoting necroptosis, were performed. As shown in Fig. 1A and B, after the cells were exposed to different concentrations $(10,20$ and $40 \mathrm{mM})$ of $\mathrm{HG}$ for $24 \mathrm{~h}$, the expression levels of RIP3 were increased in a dose-dependent manner, reaching a peak at $40 \mathrm{mM}$ glucose. Therefore, glucose at $40 \mathrm{mM}$ was used in the subsequent time-response experiment (Fig. 1C and D). The cells were exposed to $40 \mathrm{mM} \mathrm{HG}$ for $0,3,6,9,12$ and $24 \mathrm{~h}$, respectively. Following exposure of the cells to $\mathrm{HG}$ for $3 \mathrm{~h}$, the expression level of RIP3 began to increase significantly $(\mathrm{P}<0.01)$, and the maximum increase in expression level of RIP3 was observed at $9 \mathrm{~h}$. These results suggested that HG induces necroptosis in HUVECs.

$H G$ enhances the expression level of cleaved caspase-3 in HUVECs. Similarly, dose-and time -response experiments to explore the effects of different concentrations of 
A

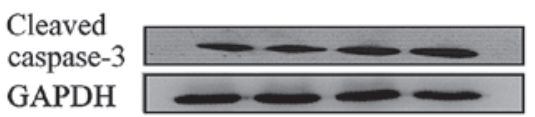

B

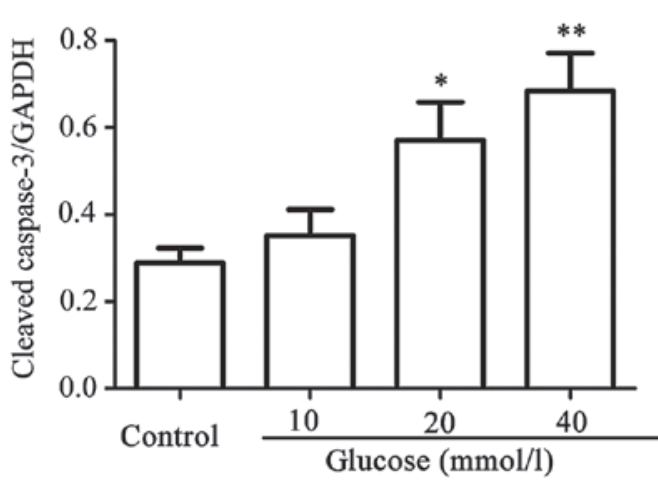

$\mathrm{C}$

Cleaved

caspase-3

GAPDH
D

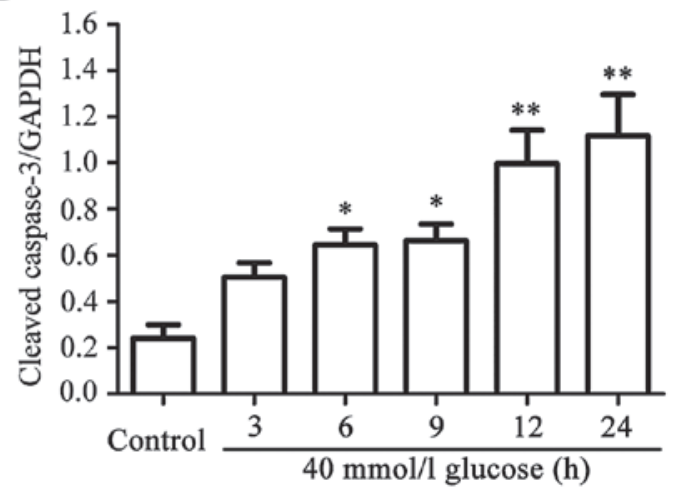

Figure 2. HG upregulates the expression levels of cleaved caspase-3 in HUVECs. The expression levels of cleaved caspase-3 were measured by western blot assay. (A) The cells were exposed to the concentrations of glucose (mmol/l) indicated in (B) for $24 \mathrm{~h}$. (C) The cells were exposed to $40 \mathrm{mM}$ glucose for the times indicated in (D). (B and D) Densitometric analysis of the expression levels of cleaved caspase-3 in (A) and (C). Data are presented as the mean \pm standard error of the mean $(\mathrm{n}=3) .{ }^{*} \mathrm{P}<0.05 ;{ }^{* *} \mathrm{P}<0.01$ vs. the control group. $\mathrm{HG}$, high glucose.

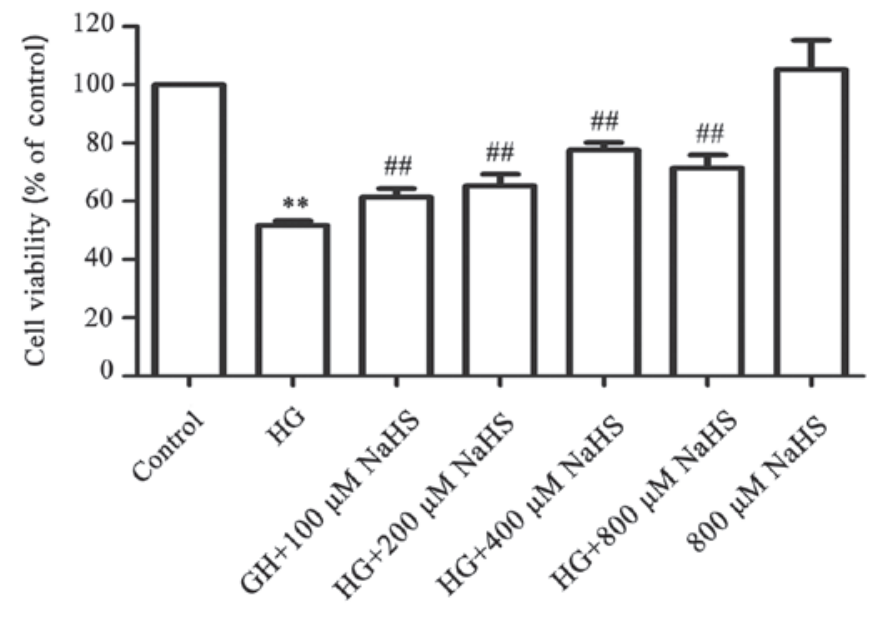

Figure $3 . \mathrm{H}_{2} \mathrm{~S}$ protects HUVECs against $\mathrm{HG}$-induced cytotoxicity. The cells were treated with or without different doses of NaHS for 30 min prior to exposure to HG for $24 \mathrm{~h}$. Cell viability was assessed using the CCK- 8 assay. Data are shown as the means \pm standard error of the mean $(\mathrm{n}=3) .{ }^{* *} \mathrm{P}<0.01$ vs. the control group; ${ }^{\# \#} \mathrm{P}<0.01$ vs. the $\mathrm{HG}$ treatment group. $\mathrm{H}_{2} \mathrm{~S}$, hydrogen sulfide; HG, high glucose; NaHS, sodium hydrogen sulfide.

glucose on the expression levels of cleaved caspase-3 in HUVECs were performed. When the cells were treated with 10,20 , and $40 \mathrm{mM}$ glucose for $24 \mathrm{~h}$, the expression level of cleaved caspase- 3 gradually increased, peaking at $40 \mathrm{mM}$ glucose (Fig. 2A and B). Furthermore, after the cells had been exposed to $40 \mathrm{mM} \mathrm{HG}$ for 3, 6, 9, 12 , and $24 \mathrm{~h}$, respectively, the expression level of cleaved caspase-3 began to evidently increase at $6 \mathrm{~h}$, reaching a maximum level at $24 \mathrm{~h}$ (Fig. 2C and D). These data indicated that HG induces apoptosis in HUVECs.

Exogenous $\mathrm{H}_{2} \mathrm{~S}$ attenuates the $\mathrm{HG}$-induced cytotoxicity in HUVECs. To examine the cytoprotective effects of $\mathrm{H}_{2} \mathrm{~S}$
A

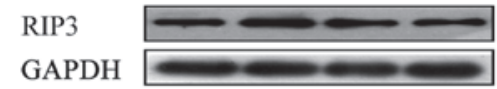

B

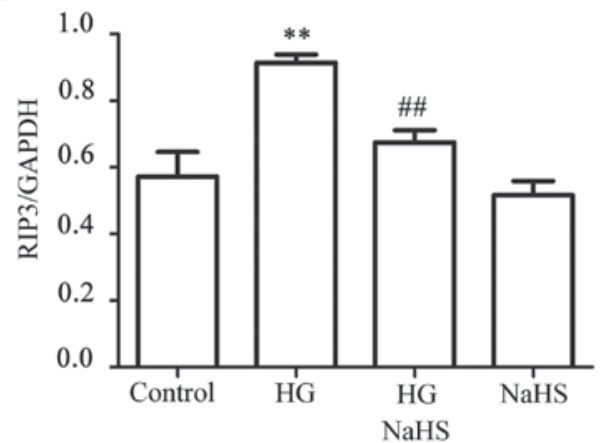

Figure 4. Exogenous $\mathrm{H}_{2} \mathrm{~S}$ ameliorates the $\mathrm{HG}$-induced increase in the expression levels of RIP3 in HUVECs. (A) HUVECs were treated with $40 \mathrm{mM}$ glucose for $9 \mathrm{~h}$ in the absence or presence of pre-treatment with $400 \mu \mathrm{M}$ NaHS for 30 min prior to exposure to HG. The expression of RIP3 was detected by western blot analysis assay. (B) Densitometric analysis of the results shown in (A). Data are presented as the means \pm standard error of the mean $(\mathrm{n}=3){ }^{* * *} \mathrm{P}<0.01$ vs. the control group; ${ }^{\# \#} \mathrm{P}<0.01$ vs. the HG-treated group. $\mathrm{H}_{2} \mathrm{~S}$, hydrogen sulfide, $\mathrm{HG}$, high glucose; RIP3, receptor-interacting protein 3 ; NaHS, sodium hydrogen sulfide.

against HG-induced cytotoxicity in HUVECs, a dose-response study with different concentrations of $\mathrm{NaHS}$ (a donor of $\mathrm{H}_{2} \mathrm{~S}$ ) was performed. As shown in Fig. 3, exposure of HUVECs to $40 \mathrm{mM}$ glucose (HG) for $24 \mathrm{~h}$ induced considerable cytotoxicity, leading to a decrease in cell viability to $51.61 \pm 1.63 \%(\mathrm{P}<0.01)$ compared with the control group. However, treatment of the cells with NaHS at 100,200,400, and $800 \mu \mathrm{M}$, respectively, for $30 \mathrm{~min}$ prior to exposure to HG markedly ameliorated the HG-induced cytotoxicity, resulting in an increase in 
A
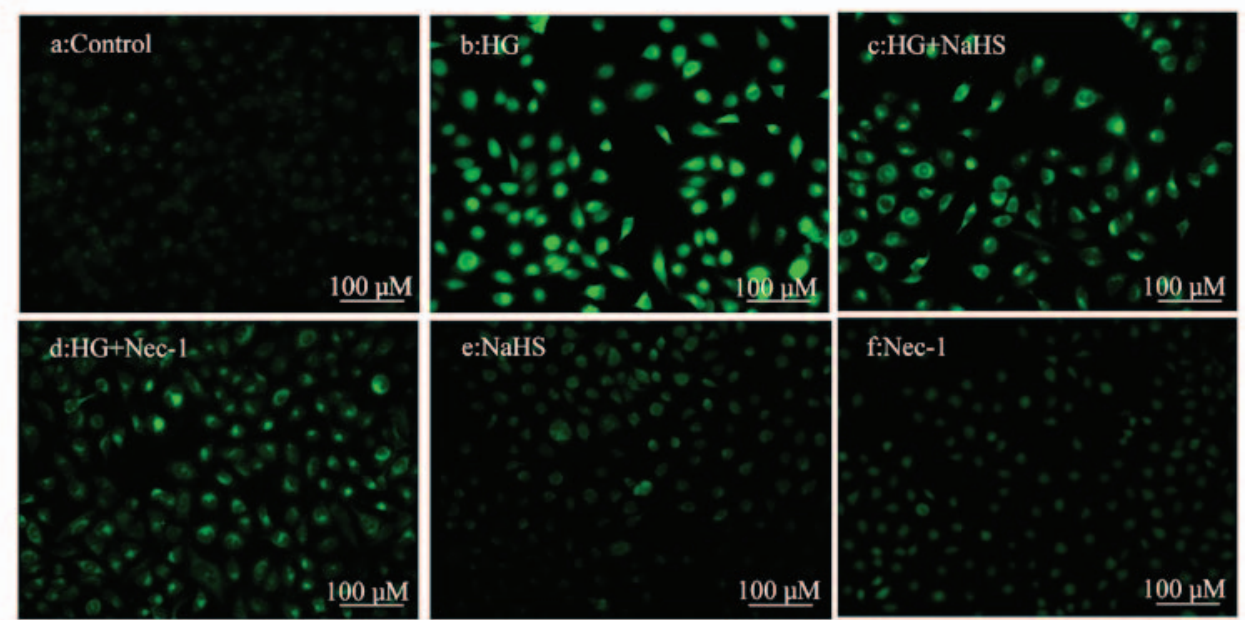

B

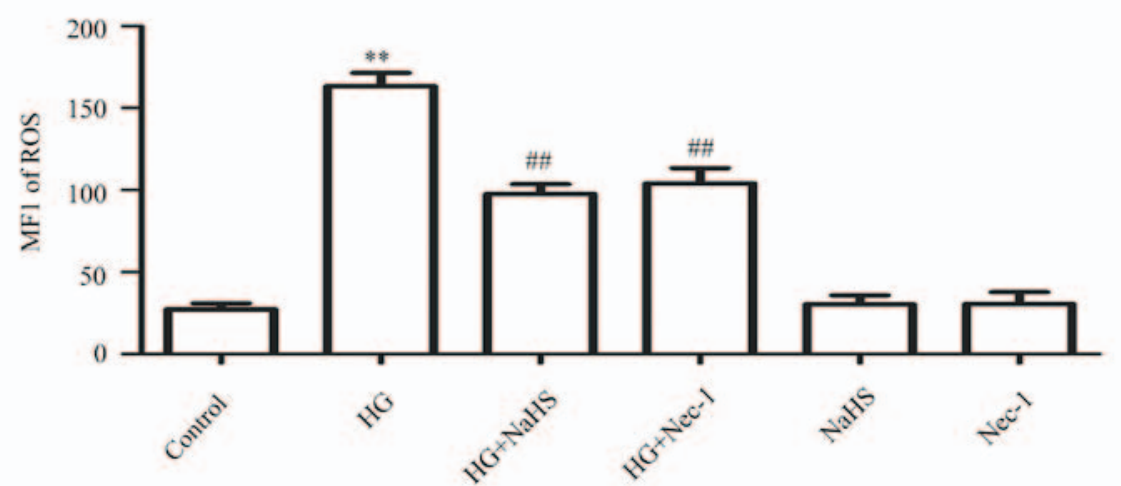

Figure 5. Exogenous $\mathrm{H}_{2} \mathrm{~S}$ attenuates HG-induced ROS generation by inhibiting necroptosis in HUVECs. (Aa-f) After the indicated treatments, the intracellular ROS level was assessed by DCFH-DA staining followed by photofluorography. (Aa) The control group. HUVECs were treated with (Ab) $40 \mathrm{mM}$ glucose for $24 \mathrm{~h}$, (Ac) $400 \mu \mathrm{M}$ NaHS for $30 \mathrm{~min}$, or (Ad) with $100 \mu \mathrm{M}$ Nec-1 for $24 \mathrm{~h}$, prior to exposure to HG. (Ae) HUVECs were treated with $400 \mu \mathrm{M}$ NaHS for $30 \mathrm{~min}$, followed by $24 \mathrm{~h}$ of culture. (Af) HUVECs were treated with $100 \mu \mathrm{M} \mathrm{Nec}-1$ for $24 \mathrm{~h}$, followed by $24 \mathrm{~h}$ of culture. (B) Quantitative analysis for the MFI of DCFH-DA in (Aa-f) with the ImageJ 1.41o software. Data are presented as mean $\pm \mathrm{SEM}(\mathrm{n}=5)$. ${ }^{* *} \mathrm{P}<0.01$ vs. the control group; ${ }^{\# \#} \mathrm{P}<0.01 \mathrm{vs}$. the HG-treated group. $\mathrm{H}_{2} \mathrm{~S}$, hydrogen sulfide; $\mathrm{HG}$, high glucose; ROS, reactive oxygen species; NaHS, sodium hydrogen sulfide; MFI, mean fluorescence intensity; Nec -1, necrostatin-1; HUVECs, human umbilical vein endothelial cells; DCFH -DA, 2',7'-dichlorofluorescein diacetate.

cell viability. The maximum protective effect was observed with $400 \mu \mathrm{M}$ NaHS. When administered alone, $800 \mu \mathrm{M}$ NaHS failed to markedly affect the cell viability of HUVECs. Based on these results, the cells were treated with $400 \mu \mathrm{M}$ NaHS for $30 \mathrm{~min}$ prior to exposure to $\mathrm{HG}$ in the following experiments.

Exogenous $\mathrm{H}_{2} \mathrm{~S}$ alleviates the $H G$-induced increase in expression of RIP3 in HUVECs. To observe the effect of exogenous $\mathrm{H}_{2} \mathrm{~S}$ on $\mathrm{HG}$-induced necroptosis, HUVECs were treated with $400 \mu \mathrm{M}$ NaHS for $30 \mathrm{~min}$ prior to exposure to $\mathrm{HG}$ for $9 \mathrm{~h}$. As shown in Fig. 4, treatment of the cells with $40 \mathrm{mM} \mathrm{HG}$ for $9 \mathrm{~h}$ markedly increased the expression level of RIP3. However, treatment of the cells with $400 \mu \mathrm{M}$ NaHS for $30 \mathrm{~min}$ prior to exposure to $\mathrm{HG}$ significantly reduced the increased expression of RIP3 induced by HG. NaHS at $400 \mu \mathrm{M}$ alone did not affect the basal expression level of RIP3. These findings revealed that exogenous $\mathrm{H}_{2} \mathrm{~S}$ inhibits the $\mathrm{HG}$-induced necroptosis in HUVECs.

Exogenous $\mathrm{H}_{2} \mathrm{~S}$ and a necroptosis inhibitor attenuate $H G$-induced oxidative stress in HUVECs. As shown in Fig. 5Ab and B, exposure of the cells to $\mathrm{HG}$ for $24 \mathrm{~h}$ markedly enhanced ROS generation. However, the increase in ROS generation was attenuated by pre-treatment of the cells with $400 \mu \mathrm{M}$ NaHS for $30 \mathrm{~min}$ prior to exposure to HG (Fig. 5Ac and B). Similarly, treatment of the cells with $100 \mu \mathrm{M} \mathrm{Nec-1} \mathrm{(an} \mathrm{inhibitor} \mathrm{of} \mathrm{necroptosis)} \mathrm{for} 24 \mathrm{~h}$ prior to exposure to $\mathrm{HG}$ also clearly blocked the increase in ROS generation (Fig. 5Ad and B). When administered alone, $400 \mu \mathrm{M}$ NaHS (Fig. 5Ae and B) or $100 \mu \mathrm{M} \mathrm{Nec}-1$ (Fig. Af and B) did not affect the basal ROS generation. These results indicated that exogenous $\mathrm{H}_{2} \mathrm{~S}$ protects HUVECs against the $\mathrm{HG}$-induced oxidative stress by inhibiting necroptosis.

Exogenous $\mathrm{H}_{2} \mathrm{~S}$ and a necroptosis inhibitor lower the $H G$-induced dissipation of MMP in HUVECs. As shown in Fig. 6, treatment of cells with $\mathrm{HG}$ for $24 \mathrm{~h}$ induced a marked dissipation of the MMP $(\mathrm{P}<0.01)$ compared with the control group (Fig. 6Aa and B). However, dissipation of the MMP was ameliorated by treatment of the cells with $400 \mu \mathrm{M}$ NaHS for $30 \mathrm{~min}$ (Fig. 6Ac and B) or $100 \mu \mathrm{M} \mathrm{Nec-1}$ 


\section{A}

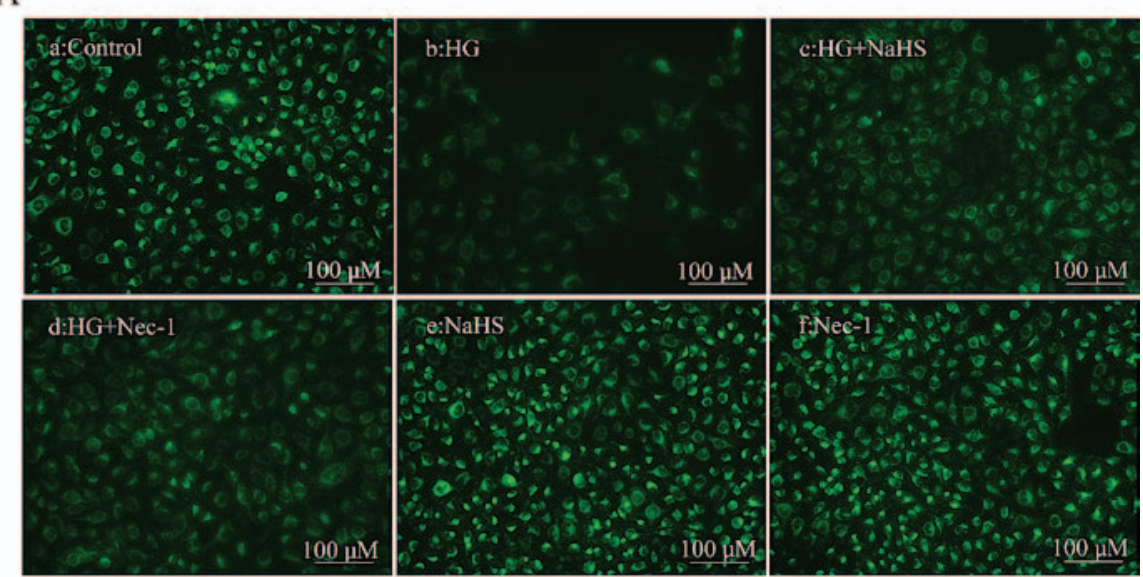

B

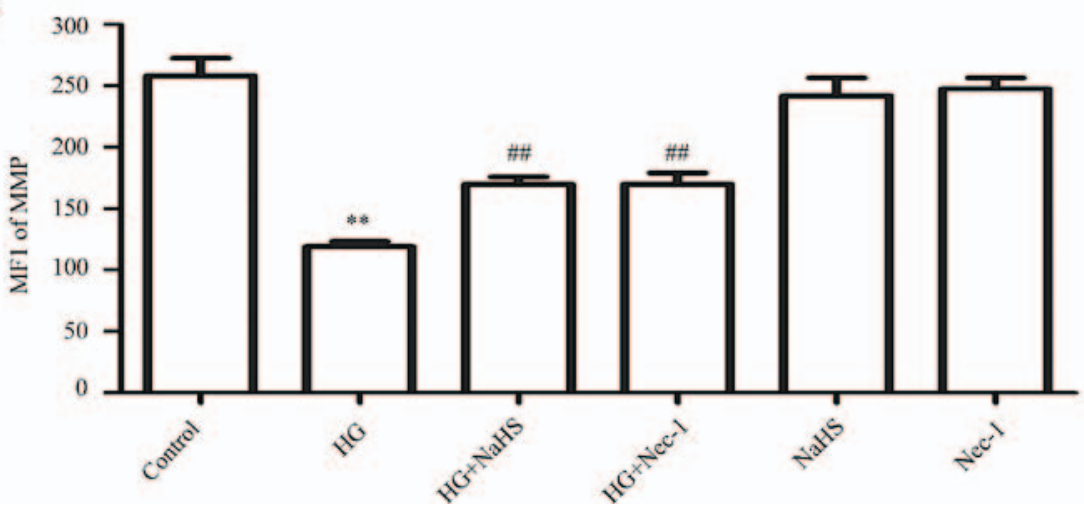

Figure 6. Exogenous $\mathrm{H}_{2} \mathrm{~S}$ alleviates the HG-induced reduction in the MMP by inhibiting necroptosis in HUVECs. (Aa-f) After the indicated treatments, the MMP was assessed by Rh123 staining, followed by photofluorography. (Aa) The control group. HUVECs were treated with (Ab) $40 \mathrm{mM}$ glucose for $24 \mathrm{~h}$, (Ac) $400 \mu \mathrm{M}$ NaHS for $30 \mathrm{~min}$, or (Ad) with $100 \mu \mathrm{M}$ Nec-1 for $24 \mathrm{~h}$ prior to exposure to HG. (Ae) HUVECs were treated with $400 \mu \mathrm{M}$ NaHS for $30 \mathrm{~min}$, followed by $24 \mathrm{~h}$ of culture. (Af) HUVECs were treated with $100 \mu \mathrm{M} \mathrm{Nec}-1$ for $24 \mathrm{~h}$, followed by $24 \mathrm{~h}$ of culture. (B) Quantitative analysis for the MFIs of Rh123 in (Aa-f) using ImageJ 1.41i software. Data are presented as the means \pm standard error of the mean $(\mathrm{n}=5)$. ${ }^{* *} \mathrm{P}<0.01$ vs. the control group; ${ }^{\# \#} \mathrm{P}<0.01 \mathrm{vs}$. the HG-treated group. $\mathrm{H}_{2} \mathrm{~S}$, hydrogen sulfide; $\mathrm{HG}$, high glucose; MMP, mitochondrial membrane potential; Rh123, rhodamine 123; ROS, reactive oxygen species; Nec-1, necrostatin-1; NaHS, sodium hydrogen sulfide; MFI, mean fluorescence intensity.

A

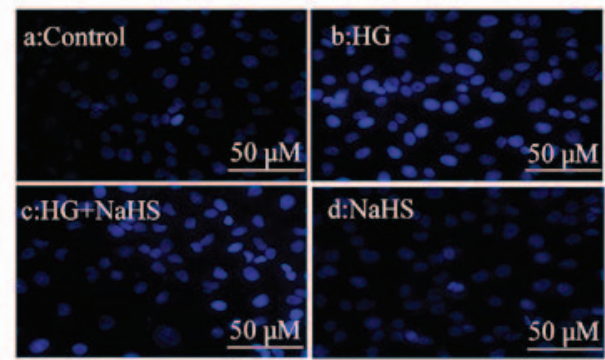

B

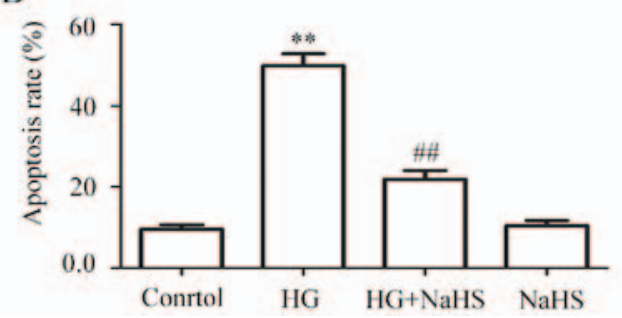

C

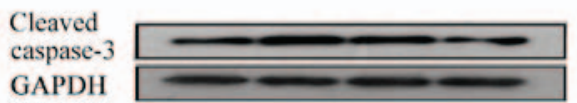

D

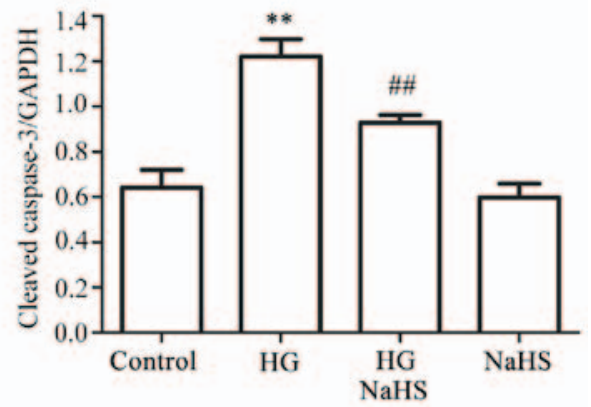

Figure 7. Exogenously added $\mathrm{H}_{2} \mathrm{~S}$ attenuates HG-induced apoptosis in the HUVECs. After the indicated treatments (Aa-d), cellular apoptosis was assessed by Hoechst 33258 staining, followed by photofluorography. (Aa) The control group. HUVECs were treated with (Ab) $40 \mathrm{mM}$ glucose for $24 \mathrm{~h}$, or with (Ac) $400 \mu \mathrm{M}$ NaHS for 30 min prior to exposure to HG. (Ad) HUVECs were treated with $400 \mu \mathrm{M}$ NaHS for 30 min followed by 24 h of culture. (B) Apoptosis was analysed with a cell counter using the ImageJ 1.410 software. (C) The expression of cleaved caspase-3 was detected by western blot analysis assay. (D) Densitometric analysis of the expression levels of cleaved caspase-3 in (C). Data are presented as the means \pm standard error of the mean ( $\mathrm{n}=3$ ). ${ }^{* *} \mathrm{P}<0.01 \mathrm{vs}$. the control group; ${ }^{\#} \mathrm{P}<0.05,{ }^{\#} \mathrm{P}<0.01$ vs. the HG-treated group. $\mathrm{HG}$, high glucose. $\mathrm{H}_{2} \mathrm{~S}$, hydrogen sulfide; HG, high glucose; NaHS, sodium hydrogen sulfide. 
A

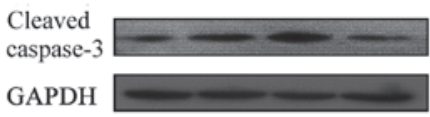

B

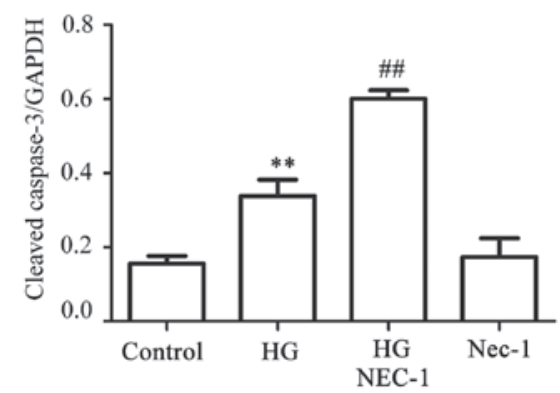

$\mathrm{C}$

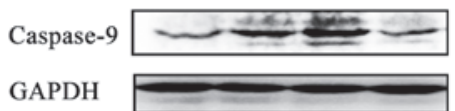

D

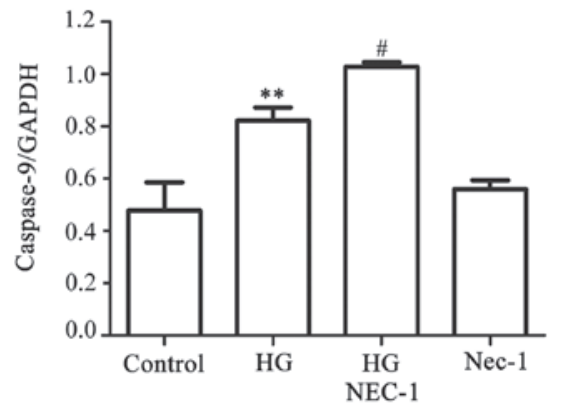

Figure 8. Nec-1 upregulates the HG-induced increase in the expression levels of cleaved caspases-3 and -9 in HUVECs. (A and C) HUVECs were treated with $40 \mathrm{mM}$ glucose for $24 \mathrm{~h}$ in the absence or presence of pre-treatment with $100 \mu \mathrm{M} \mathrm{Nec}-1$ for $24 \mathrm{~h}$, prior to exposure to HG. The expression of cleaved caspases-3 and -9 was detected by western blot assay. (B and D) Densitometric analysis for the results shown in (A and C). Data are presented as the means \pm standard error of the mean. $(\mathrm{n}=3)$. ${ }^{* *} \mathrm{P}<0.01$ vs. the control group; ${ }^{\#} \mathrm{P}<0.05,{ }^{\# \#} \mathrm{P}<0.01$ vs. the HG-treated group. Nec-1, necrostatin-1; HG, high glucose.

A

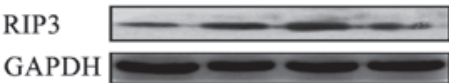

B

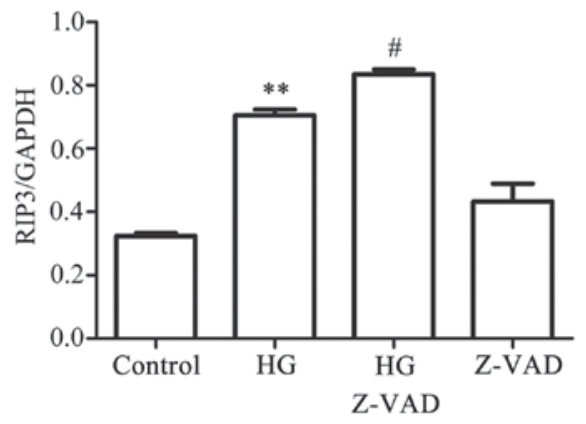

Figure 9. Z-VAD-FMK ameliorates the HG-induced increase in the expression levels of RIP3 in HUVECs. (A) HUVECs were treated with $40 \mathrm{mM}$ glucose for $9 \mathrm{~h}$ in the absence or presence of pre-treatment with $20 \mu \mathrm{M}$ Z-VAD-FMK (a pan -caspase inhibitor) for $30 \mathrm{~min}$ prior to exposure to HG. The expression of RIP3 was detected by western blot analysis assay. (B) Densitometric analysis for the results shown in (A). Data are presented as the means \pm standard error of the mean $(n=3)$. ${ }^{* *} \mathrm{P}<0.01$ vs. the control group; ${ }^{~} \mathrm{P}<0.05$ vs. the HG-treated group. HG, high glucose; RIP3, receptor -interacting protein 3 .

for $24 \mathrm{~h}$ (Fig. 6Ad and B) prior to exposure to $\mathrm{HG}$ for $24 \mathrm{~h}$. When administered alone, $400 \mu \mathrm{M}$ NaHS (Fig. 6Ae and B) or $100 \mu \mathrm{M} \mathrm{Nec-1} \mathrm{(Fig.} \mathrm{6Af} \mathrm{and} \mathrm{B)} \mathrm{failed} \mathrm{to} \mathrm{elicit} \mathrm{a} \mathrm{loss} \mathrm{of}$ MMP. These data demonstrated that exogenous $\mathrm{H}_{2} \mathrm{~S}$ protects HUVECs against the HG-induced dissipation of MMP by inhibiting necroptosis.

Exogenous $\mathrm{H}_{2} \mathrm{~S}$ reduces $\mathrm{HG}$-induced apoptosis in the HUVECs. The data obtained from the experiment of Hoechst 33258 staining followed by photofluorography revealed that exposure of the cells to $\mathrm{HG}$ for $24 \mathrm{~h}$ markedly increased the number of apoptotic cells (Fig. 7Ab and B)
$(\mathrm{P}<0.01)$ compared with the control group (Fig. 7Aa and $\mathrm{B})$. However, the increased number of apoptotic cells was reduced by treatment of the cells with $400 \mu \mathrm{M} \mathrm{NaHS}$ for $30 \mathrm{~min}$ prior to exposure to HG (Fig. 7Ac and B). Similarly, pre-treatment with $400 \mu \mathrm{M}$ NaHS also inhibited the HG-induced increase in the expression level of cleaved caspase-3 (Fig. 7C and D). NaHS at $400 \mu \mathrm{M}$ alone did not affect the number of apoptotic cells or the basal expression level of cleaved caspase-3 (Fig. 7Ad, B -D).

A negative interaction exists between necroptosis and apoptosis in the HG-treated HUVECs. Since it has been reported that $\mathrm{Nec}-1$, an inhibitor of necroptosis, converts shikonin-induced necroptosis into apoptosis in HL60 cells (25), it appeared reasonable to explore whether, in the presence of Nec-1, HG-induced necroptosis was reverted to apoptosis in HUVECs. As indicated in Fig. 8A and C, exposure of the cells to $\mathrm{HG}$ for $24 \mathrm{~h}$ markedly increased the expression levels of cleaved caspases-3 and -9. Of note, treatment of the cells with $100 \mu \mathrm{mol} \mathrm{Nec}-1$ for $24 \mathrm{~h}$ prior to exposure to HG further promoted the increase in the expression of cleaved caspases-3 and -9 . When administered alone, $100 \mu \mathrm{mol} \mathrm{Nec-1}$ did not affect the basal expression level of cleaved caspases-3 and -9 . On the other hand, treatment of the cells with $20 \mu \mathrm{mol} \mathrm{Z-VAD-FMK}$, a pan -caspase inhibitor, for 30 min prior to exposure to $\mathrm{HG}$ for $9 \mathrm{~h}$ further promoted the increased expression level of RIP3 induced by HG. When administered alone, Z-VAD-FMK did not affect the basal expression level of RIP3 (Fig. 9A and B). Collectively, these results suggested that there was a negative interaction between necroptosis and apoptosis in the HG-treated HUVECs: On the one hand, necroptosis inhibited apoptosis, whereas on the other, apoptosis suppressed necroptosis.

\section{Discussion}

Necroptosis (programmed necrosis) represents a newly identified mechanism of cell death, combining features of 
both apoptosis and necrosis. Increasing evidence has indicated the involvement of necroptosis in a variety of pathological conditions, including diabetic cardiac injury (23) and development of atherosclerosis (24). However, the roles of necroptosis in HG-induced vascular endothelial injury, and in the protection afforded by exogenously added $\mathrm{H}_{2} \mathrm{~S}$ are, at present, unclear. The present study clearly demonstrated the following effects of HG-treatment of the HUVECs: i) HG significantly enhanced the expression level of RIP3, a kinase promoting necroptotic cell death; ii) Nec-1, an inhibitor of necroptosis, attenuated the $\mathrm{HG}$-induced injury, including ROS generation and a loss of MMP; iii) a negative interaction between necroptosis and apoptosis was observed; on the one hand, Nec-1 increased the expression level of cleaved caspase-3, whereas on the other, Z-VAD-FMK, a pan -caspase inhibitor, upregulated the expression level of RIP3; iv) exogenous $\mathrm{H}_{2} \mathrm{~S}$ ameliorated the HG-induced increase in the expression level of RIP3 and endothelial injury, leading to an increase in cell viability and a decrease in the number of apoptotic cells and the expression level of cleaved caspase-3, ROS generation, as well as dissipation of MMP. Taken together, the findings of the present study have provided, to the best of our knowledge, the first evidence that necroptosis mediates HG-induced injury, and that the inhibition of necroptosis contributes to the protective effect of exogenous $\mathrm{H}_{2} \mathrm{~S}$ against $\mathrm{HG}$-induced injury in HUVECs.

Hyperglycemia is a risk factor associated with vascular dysfunction, resulting in various vascular diseases, which may be a contributor towards morbidity and mortality in diabetic patients $(26,27)$. Thus, further exploration of the mechanisms underlying hyperglycemia-induced vascular endothelial injury is very important for the prevention and treatment of diabetic complications, such as retinopathy (28) and nephropathy (29). Multiple factors have been revealed to contribute towards hyperglycemia-elicited vascular endothelial damage, for example, ROS generation (5), mitochondrial damage (5), and cell death, including apoptosis and necrosis (30). Recently, a novel mechanism termed necroptosis or 'programmed necrosis' has been suggested as another critical mediator of cell death in the heart (31). In vitro studies have demonstrated that tumor necrosis factor- $\alpha$-dependent formation of a complex between RIP1 and RIP3 is an important step for the induction of necroptosis $(32,33)$. In this process, RIP3 appears to exert a key role, controlling RIP1 phosphorylation $(33,34)$. However, although a recent study has indicated that RIP3 is overexpressed in diabetic myocardial tissue (23), the effect of hyperglycemia on RIP3 in the vascular endothelial cells remains unclear. To investigate this, dose- and time-response experiments to determine the expression level of RIP3 were performed in the HG-treated HUVECs. The data from these experiments revealed that exposure of the cells to HG significantly upregulated the expression level of RIP3, suggesting the induction of necroptosis in the HG-treated HUVECs. Combining our results with the findings reported by Liu et al (23), it was revealed that hyperglycemia may be a strong stimulus for inducing necroptosis in the cardiovascular tissues.

That necroptosis has been demonstrated to be implicated in ischemia-induced cardiac lesions $(10,35)$ and the development of atherosclerosis (24) inspired us to explore the role of necroptosis in HG-triggered injury in the endothelial cells.
Consistently with a previously published study (6), the results of the present study demonstrated that exposure of HUVECs to HG induced multiple injuries, as indicated by a decrease in cell viability and an increase in the number of apoptotic cells, the expression level of cleaved caspase-3, ROS generation, as well as dissipation of MMP. However, treatment of the cells with Nec-1 (an inhibitor of necroptosis) prior to exposure to $\mathrm{HG}$ markedly attenuated HG-induced injury, leading to a decrease in ROS generation, as well as a loss of MMP. These results suggested that necroptosis is involved in $\mathrm{HG}$-induced injury in HUVECs, which may be a novel mechanism responsible for hyperglycemia-induced vascular endothelial injury.

It has been indicated previously that necroptosis may function as a cellular 'backup' mechanism to ensure the elimination of damaged cells under certain conditions when apoptosis is inhibited $(6,36)$. RIP3 has been reported to participate in mediation of apoptosis and necrosis (37). In addition, results from a recent study revealed that the presence of Nec-1 shifts shikonin-induced necroptosis to apoptosis (25). Based on other published studies $(6,36-38)$, the present study aimed to explore further the interaction between necroptosis and apoptosis in the HG-treated HUVECs. The results demonstrated that pre-treatment with Z-VAD-FMK (an inhibitor of caspase) prior to the exposure of HUVECs to HG may markedly enhance the expression level of RIP3. It is noteworthy that pre-treatment with Nec-1 prior to exposure of the cells to HG clearly upregulated the expression of cleaved caspases-3 and -9. These findings suggested that there is a negative interaction between necroptosis and apoptosis in the HG-treated HUVECs. The results of the present study are supported by other recent studies $(6,36,38)$. However, Zhang et al $(37)$ demonstrated that Nec-1 attenuates the expression level of cleaved caspase- 3 in 11'-deoxyverticillin A (C42)-treated human colon cell lines. The reasons underlying this different conclusion are complex, although one possible explanation may be concerned with the different experimental models and different cell lines used.

Another novel finding of the present study is associated with the contribution of necroptosis to the protective effect of exogenous $\mathrm{H}_{2} \mathrm{~S}$ against HG-induced injury in HUVECs. $\mathrm{H}_{2} \mathrm{~S}$, as an endogenously produced gas transmitter, is cardiovascular-protective $(6,11-22,38,39)$. Accumulating evidence has indicated that exogenous $\mathrm{H}_{2} \mathrm{~S}$ protects cardiac cells against the HG-induced injury $(16,18) . \mathrm{H}_{2} \mathrm{~S}$ replacement also improves endothelial function in hyperglycemic endothelial cells and in diabetic rats (5). In agreement with a previously published study (5), the findings of the present study demonstrated that exposure of HUVECs to HG induced multiple injuries, including cytotoxicity, an increase in the number of apoptotic cells and the expression level of cleaved caspase-3, ROS generation, as well as a loss of MMP. However, exogenous $\mathrm{H}_{2} \mathrm{~S}$ protected the cells against the above injuries. Importantly, the results of the present study demonstrated that exogenous $\mathrm{H}_{2} \mathrm{~S}$ markedly alleviated the increased expression of RIP3 by HG, suggesting an inhibitory effect of exogenous $\mathrm{H}_{2} \mathrm{~S}$ on $\mathrm{HG}$-induced necroptosis. Also taking into consideration with these results our finding that necroptosis mediates HG-induced HUVEC injury, the present study supports a novel hypothesis that inhibition of necroptosis may be one of the key mechanisms underlying the protective effect of $\mathrm{H}_{2} \mathrm{~S}$ against the HG-induced endothelial injury. 
In conclusion, the present study has highlighted the role of necroptosis in HG-induced endothelial cell injury, and its potential clinical significance. Hence, necroptosis may become a novel therapeutic target when establishing treatment strategies. Crucially, it has been demonstrated, to the best of our knowledge for the first time, that exogenous $\mathrm{H}_{2} \mathrm{~S}$ protects HUVECs against HG-induced injury by inhibiting the necroptosis pathway. Furthermore, in spite of the identification of the interaction between necroptosis and apoptosis, it may not be assumed that the inhibition of necroptosis or apoptosis does not mean prevention of the cells from mortality. Rather, it has been demonstrated that $\mathrm{H}_{2} \mathrm{~S}$ may inhibit both apoptosis and necroptosis, suggesting that it is a favorable protective agent. Thus, exogenous $\mathrm{H}_{2} \mathrm{~S}$ may be a major factor to take into consideration when developing novel therapeutic strategies for the prevention and treatment for diabetic cardiovascular complications.

\section{Acknowledgements}

The present study was supported by grants from the National Natural Science Foundation of China (no. 81450062) and Natural Science Foundation of Guangdong Province, China (no. 2015A030313872).

\section{References}

1. Mohsen L, Abou-Alam M, El-Dib M, Labib M, Elsada M and Aly H: A prospective study on hyperglycemia and retinopathy of prematurity. J Perinatol 34: 453-457, 2014.

2. Ghosh SS, Righi S, Krieg R, Kang L, Carl D, Wang J, Massey HD, Sica DA, Gehr TW and Ghosh S: High fat high cholesterol diet (western diet) aggravates atherosclerosis, hyperglycemia and renal failure in nephrectomized LDL receptor knockout mice: role of intestine derived lipopolysaccharide. PLoS One 10: e0141109, 2015.

3. Laakso M and Kuusisto J: Insulin resistance and hyperglycaemia in cardiovascular disease development. Nat Rev Endocrinol 10: 293-302, 2014

4. Cal L, Li W, Wang G, Guo L, Jiang Y and Kang YJ: Hypergly cemia-induced apoptosis in mouse myocardium: Mitochondria cytochrome C-mediated caspase-3 activation pathway. Diabetes 51: 1938-1948, 2002.

5. Suzuki K, Olah G, Modis K, Coletta C, Kulp G, Gerö D, Szoleczky P, Chang T, Zhou Z, Wu L, et al: Hydrogen sulfide replacement therapy protects the vascular endothelium in hyperglycemia by preserving mitochondrial function. Proc Natl Acad Sci USA 108: 13829-13834, 2011.

6. Degterev A, Huang Z, Boyce M, Li Y, Jagtap P, Mizushima N, Cuny GD, Mitchison TJ, Moskowitz MA and Yuan J: Chemical inhibitor of nonapoptotic cell death with therapeutic potential for ischemic brain injury. Nat Chem Biol 1: 112-119, 2005.

7. Han J, Zhong CQ and Zhang DW: Programmed necrosis: Backup to and competitor with apoptosis in the immune system. Nat Immunol 12: 1143-1149, 2011.

8. Smith CC and Yellon DM: Necroptosis, necrostatins and tissue injury. J Cell Mol Med 15: 1797-1806, 2011.

9. Dvoriantchikova G, Degterev A and Ivanov D: Retinal ganglion cell (RGC) programmed necrosis contributes to ischemia-reperfusion-induced retinal damage. Exp Eye Res 123: 1-7, 2014.

10. Oerlemans MI, Liu J, Arslan F, den Ouden K, van Middelaar BJ, Doevendans PA and Sluijter JP: Inhibition of RIP1-dependent necrosis prevents adverse cardiac remodeling after myocardial ischemia-reperfusion in vivo. Basic Res Cardiol 107: 270, 2012.

11. Zhao W, Zhang J, Lu Y and Wang R: The vasorelaxant effect of $\mathrm{H}(2) \mathrm{S}$ as a novel endogenous gaseous K(ATP) channel opener. EMBO J 20: 6008-6016, 2001.

12. Yang G, Wu L, Jiang B, Yang W, Qi J, Cao K, Meng Q, Mustafa $\mathrm{AK}, \mathrm{Mu} \mathrm{W}$, Zhang $\mathrm{S}$, et al: $\mathrm{H}_{2} \mathrm{~S}$ as a physiologic vasorelaxant: Hypertension in mice with deletion of cystathionine gamma-lyase. Science 322: 587-590, 2008.
13. Papapetropoulos A, Pyriochou A, Altaany Z, Yang G, Marazioti A, Zhou Z, Jeschke MG, Branski LK, Herndon DN, Wang R, et al: Hydrogen sulfide is an endogenous stimulator of angiogenesis. Proc Natl Acad Sci USA 106: 21972-21977, 2009.

14. Calvert JW, Elston M, Nicholson CK, Gundewar S, Jha S, Elrod JW, Ramachandran A and Lefer DJ: Genetic and pharmacologic hydrogen sulfide therapy attenuates ischemia-induced heart failure in mice. Circulation 122: 11-19, 2010.

15. Wang X, Wang Q, Guo W and Zhu YZ: Hydrogen sulfide attenuates cardiac dysfunction in a rat model of heart failure: A mechanism through cardiac mitochondrial protection. Biosci Rep 31: 87-98, 2011.

16. Xu W, Wu W, Chen J, Guo R, Lin J, Liao X and Feng J: Exogenous hydrogen sulfide protects $\mathrm{H} 9 \mathrm{c} 2$ cardiac cells against high glucose-induced injury by inhibiting the activities of the p38 MAPK and ERK1/2 pathways. Int J Mol Med 32: 917-925, 2013.

17. Wang XY, Yang CT, Zheng DD, Mo LQ, Lan AP, Yang ZL, Hu F, Chen PX, Liao XX and Feng JQ: Hydrogen sulfide protects H9c2 cells against doxorubicin-induced cardiotoxicity through inhibition of endoplasmic reticulum stress. Mol Cell Biochem 363: 419-426, 2012.

18. Xu W, Chen J, Lin J, Liu D, Mo L, Pan W, Feng J, Wu W and Zheng D: Exogenous $\mathrm{H}_{2} \mathrm{~S}$ protects $\mathrm{H} 9 \mathrm{c} 2$ cardiac cells against high glucose-induced injury and inflammation by inhibiting the activation of the NF- $\kappa \mathrm{B}$ and IL-1 $1 \beta$ pathways. Int J Mol Med 35: 177-186, 2015.

19. Liang W, Chen J, Mo L, Ke X, Zhang W, Zheng D, Pan W, Wu S, Feng J, Song M, et al: ATP-sensitive $\mathrm{K}^{+}$channels contribute to the protective effects of exogenous hydrogen sulfide against high glucose-induced injury in H9c2 cardiac cells. Int J Mol Med 37: 763-772, 2016.

20. Mani S, Li H, Untereiner A, Wu L, Yang G, Austin RC, Dickhout JG, Lhoták Š, Meng QH and Wang R: Decreased endogenous production of hydrogen sulfide accelerates atherosclerosis. Circulation 127: 2523-2534, 2013.

21. Zhang H, Guo C, Wu D, Zhang A, Gu T, Wang L and Wang C: Hydrogen sulfide inhibits the development of atherosclerosis with suppressing CX3CR1 and CX3CL1 expression. PLoS One 7: e41147, 2012

22. Jain SK, Bull R, Rains JL, Bass PF, Levine SN, Reddy S, McVie R and Bocchini JA Jr: Low levels of hydrogen sulfide in the blood of diabetes patients and streptozotocin-treated rats causes vascular inflammation? Antioxid Redox Signal 12: 1333-1337, 2010.

23. Liu YS, Huang ZW, Wang L, Liu XX, Wang YM, Zhang Y and Zhang M: Sitagliptin alleviated myocardial remodeling of the left ventricle and improved cardiac diastolic dysfunction in diabetic rats. J Pharmacol Sci 127: 260-274, 2015.

24. Lin J, Li H, Yang M, Ren J, Huang Z, Han F, Huang J, Ma J, Zhang D, Zhang Z, et al: A role of RIP3-mediated macrophage necrosis in atherosclerosis development. Cell Reports 3: 200-210, 2013.

25. Han W, Xie J, Li L, Liu Z and Hu X: Necrostatin-1 reverts shikonin-induced necroptosis to apoptosis. Apoptosis 14: 674-686, 2009

26. Ruderman NB, Williamson JR and Brownlee M: Glucose and diabetic vascular disease. FASEB J 6: 2905-2914, 1992.

27. van Dieren S, Beulens JW, van der Schouw YT, Grobbee DE and Neal B: The global burden of diabetes and its complications: An emerging pandemic. Eur J Cardiovasc Prev Rehabil 17 (Suppl 1): S3-S8, 2010

28. Kern TS, Tang J, Mizutani M, Kowluru RA, Nagaraj RH, Romeo G, Podesta F and Lorenzi M: Response of capillary cell death to aminoguanidine predicts the development of retinopathy: Comparison of diabetes and galactosemia. Invest Ophthalmol Vis Sci 41: 3972-3978, 2000.

29. Zhang X, Liang D, Lian X, Jiang Y, He H, Liang W, Zhao Y and Chi ZH: Berberine activates Nrf2 nuclear translocation and inhibits apoptosis induced by high glucose in renal tubular epithelial cells through a phosphatidylinositol 3-kinase/Akt-dependent mechanism. Apoptosis 21: 721-736, 2016.

30. Frustaci A, Kajstura J, Chimenti C, Jakoniuk I, Leri A, Maseri A, Nadal-Ginard B and Anversa P: Myocardial cell death in human diabetes. Circ Res 87: 1123-1132, 2000.

31. Kung G, Konstantinidis K and Kitsis RN: Programmed necrosis, not apoptosis, in the heart. Circ Res 108: 1017-1036, 2011.

32. He S, Wang L, Miao L, Wang T, Du F, Zhao L and Wang X: Receptor interacting protein kinase-3 determines cellular necrotic response to TNF-alpha. Cell 137: 1100-1111, 2009. 
33. Cho YS, Challa S, Moquin D, Genga R, Ray TD, Guildford M and Chan FK: Phosphorylation-driven assembly of the RIP1-RIP3 complex regulates programmed necrosis and virus-induced inflammation. Cell 137: 1112-1123, 2009.

34. Declercq W, Vanden Berghe T and Vandenabeele P: RIP kinases at the crossroads of cell death and survival. Cell 138: 229-232, 2009.

35. Smith CC, Davidson SM, Lim SY, Simpkin JC, Hothersall JS and Yellon DM: Necrostatin: A potentially novel cardioprotective agent? Cardiovasc Drugs Ther 21: 227-233, 2007.

36. Holler N, Zaru R, Micheau O, Thome M, Attinger A, Valitutti S, Bodmer JL, Schneider P, Seed B and Tschopp J: Fas triggers an alternative, caspase-8-independent cell death pathway using the kinase RIP as effector molecule. Nat Immunol 1: 489-495, 2000.

37. Zhang N, Chen Y, Jiang R, Li E, Chen X, Xi Z, Guo Y, Liu X, Zhou Y, Che Y, et al: PARP and RIP 1 are required for autophagy induced by 11'-deoxyverticillin A, which precedes caspase-dependent apoptosis. Autophagy 7: 598-612, 2011.
38. Xu S, Liu Z and Liu P: Targeting hydrogen sulfide as a promising therapeutic strategy for atherosclerosis. Int J Cardiol 172: 313-317, 2014

39. Mani S, Untereiner A, Wu L and Wang R: Hydrogen sulfide and the pathogenesis of atherosclerosis. Antioxid Redox Signal 20: 805-817, 2014.

This work is licensed under a Creative Commons Attribution-NonCommercial-NoDerivatives 4.0 International (CC BY-NC-ND 4.0) License. 